Inevitably, the treatment of the factual sections differs little from that in Romer's book. The chapter on the muscular system is less easy to follow in Pirlot's book; this would have been improved by the addition of a table of homologies and by the use of more diagrammatic figures instead of drawings taken from dissections. The detailed descriptions of the circulatory systems of the dogfish, frog and cat would have seemed more appropriate in a dissection guide; this chapter does, however, contain a useful section on the adaptation of muscle systems to particular requirements. Here, and at several other points, Pirlot gives a brief but useful discussion of a related topic of general interest-others include the relationship between lateral-line canals and dermal bones, the homology and development of the swim-bladder and the origin of paired fins. Pirlot also includes two useful general chapters. One deals with the contribution of comparative osteology to evolutionary theory; it considers several aspects of growth, ontogeny vs. phylogeny, orthogenesis, parallelism and convergence, extinction, the rate of evolutionary change, and the like. The other general chapter considers the relationships between comparative morphology and neighbouring disciplines, such as physiology, ecology and genetics.

Many of the illustrations are novel or re-drawn and proride a welcome new selection; those by Mlle Janet Peace are especially good. Two practices, however, make them unnecessarily difficult to follow. It is unfortunate that the information about each is provided only in the legend beneath - which, as a result, is often too long. It would have been far more convenient if the name of its owner had appeared immediately below, for example, each of the eight pelvic girdlos shown on one illustration, instead of in the legend. Similarly, it would often have been possible to show the name of a structure beside the identification arrow or, at least, a well chosen abbrevia. tion which might have reminded the reader of its name. Instead, these are indicated by numbers, and the reader must again search through the legend to identify the structures. In general, Pirlot's book is less profusely illustrated than Romer's, and many of his illustrations are less clear.

The type used in Pirlot's book is somewhat larger than that in Romer's, which gives the pages a more attractive, "open" appearance. Together with the slightly thicker paper, however, this has resulted in a book which is over one and a half times as long and nearly twice as thick, so that it is physically far more unwieldy.

None of the criticisms mentioned above are of funda. mental importance, and Pirlot's text is clear, compre hensive and up to date. It should certainly be welcomed by French-speaking students on both sides of the Atlantic, though it seems likely that the Anglo-Saxons will, as usual, stick together-and to Romer.

BARRY COX

\section{PROTOZOA FOR THE LAYMAN}

\section{The Marvellous Animals}

An Introduction to the Protozoa. By Helena Curtis. Drawings by Shirley Baty. Pp. xvi + 189. (Heinemann (Educational): London, September 1969.) $35 s$.

Ever since Antony van Leeuwenhoek first saw Protozoa with his elementary microscope nearly three centuries ago, microscopists have been fascinated by these "marvellous animals". Many have spoken of their enchantment - even busy scientists of the present generation may easily be bewitched into spending hours just watching them. Clearly the author of this book has fallen under this spell.

There has been an enormous growth in our knowledge of the structure and physiology of Protozoa in the past decade or two. We must not expect then that a book of this size, written for the layman, should be a complete guide to modern protozoology. Rather, it is a series of glimpses of interesting features of the structure and life of some of the best studied members of the group. The examples include observations from many sources, ranging from some made by Leeuwenhoek himself to recent studies with the electron microscope; they are well chosen and generally give a good picture of the sorts of organisms that protozoologists study. On the whole the accounts are accurate and clear, but there are some curious errors. such as allowing Peranema only one long flagellum and providing Leishmania with two; an omission in the gregarine life cycle described on page 150 may cause some confusion, and the author falls into the familiar trap of suggesting that the mating types of Paramecium should in some way be equated with sexes, when, of course, each Paramecium is hermaphrodite. The book is illustrated with photographs and with a number of admirably simple drawings, most of which convey clearly the point intended. Most of the micrographs and electron micrographs also make their point adequately, especially where acconpanied by interpretive drawings. The publishers are to be congratulated on a well produced book, but it is regretted that generic names are not given in italies, although specific names are.

There is no intention that this should be a textbookthere are no complete descriptions of any organism or any group-but the reader is referred in a short biblio. graphy to most of the best modern books on Protozoa. Although in some places the explanations may be more colourfully worded, and the answers more clear-cut, than many scientific protozoologists would approve, the bonk is written in a very easy flowing style, and it is certainly worthy of a place on the bookshelves of the naturalist, microscopist or school biology library. M. A. SLEIGH

\section{LEARNING BY LOOKING}

\section{Hamlyn All-Colour Paperbacks}

(Hamlyn: London; Sunbooks: Melbourne, August 1969.) $6 s$ each.

Bird Behaviour. By John Sparks. Pp. 159. Fishes of the World. By Allan Cooper. Pp. 160. Life in the Sea. By John Croft. Pp. 159. Natural History Collecting. By Reg Harris. Pp. 159. Prehistoric Animals. By Barry Cox. Pp. 160. Fossil Man. By Michael H. Day. Pp. 159. Snakes of the World. By John Studworthy. Pp. 159. A Guide to the Seashore. By Ray Ingle. Pp. 159. Pets for Children. By Stephanie Denham and Ken Denham. Pp. 159. Garden Shrubs. By Peter Hunt. Pp. 159. Trains. By John R. Day. Pp. 159. Sailing Ships and Sailing Crafi. By George Goldsmith-Carter. Pp. 159. Atomic Energy. By Matthew J. Gaines. Pp. 159. Mathematics. By Charles Solomon. Pp. 159.

'THE Financial Times has reported that the Paul Hamlyn Publishing Group has so far invested three years' work and over $£ 1$ million in its all-colour paperback series which will eventually comprise 140 titles. Moreover, deals with overseas publishers are said to be worth over \$1 million in advance royalties and a specially recruited sales force backed by $£ 50,000$ worth of advertising is assaulting the home market. With such promotion, which is customarily associated with new models from Detroit or Dagenham. the series seems bound to be a commercial success. After reading a sample of the first twenty-four books I think on the whole that the series will deserve its success.

The publishers of course make much of the fact that their six shilling books are the only paperbacks to bo printed in colour. That means that there are coloured drawings, graphs and even mathematical equations on two out of three pages. No doubt the need to cut costs dictated the use of drawings rather than photographs throughout and in many cases this is an advantage. 